\title{
Sex differences in gene expression patterns associated with
}

\section{the APOE4 allele [version 1; peer review: 1 approved, 1}

\section{approved with reservations]}

\author{
Michelle Hsu1*, Mehek Dedhia1* ${ }^{*}$ Wim E Crusio (iD) 2 Anna Delprato (D)1 \\ ${ }^{1}$ Department of Research and Education, BioScience Project, Wakefield, MA, 01880, USA \\ ${ }^{2}$ Institut de Neurosciences Cognitives et Intégratives d'Aquitaine, UMR, CNRS and University of Bordeaux, UMR 5287, Pessac cedex, \\ Aquitaine, 33615, France \\ ${ }^{*}$ Equal contributors
}

V1 First published: 05 Apr 2019, 8:387

https://doi.org/10.12688/f1000research.18671.1

Latest published: $23 \mathrm{Jul}$ 2019, 8:387

https://doi.org/10.12688/f1000research.18671.2

\section{Abstract}

Background: The APOE gene encodes apolipoprotein $\varepsilon$ (ApoE), a protein that associates with lipids to form lipoproteins that package and traffic cholesterol and lipids through the bloodstream. There are at least three different alleles of the $A P O E$ gene: $A P O E 2, A P O E 3$, and $A P O E 4$. The APOE4 allele increases an individual's risk for developing late-onset Alzheimer disease (AD) in a dose-dependent manner. Sex differences have been reported for AD susceptibility, age of onset, and symptom progression, with females being more affected than males. Methods: In this study, we use a systems biology approach to examine gene expression patterns in the brains of aged female and male individuals who are positive for the APOE4 allele in order to identify possible sex-related differences that may be relevant to AD. Results: Based on correlation analysis, we identified a large number of genes with an expression pattern similar to that of APOE in APOE4positive individuals. The number of these genes was much higher in APOE4-positive females than in APOE4-positive males, who in turn had more of such genes than APOE4-negative control groups.

Conclusions: Profiling of these genes using Gene Ontology (GO) term classification, pathway enrichment, and differential expression analysis supports the idea of a transcriptional role of $A P O E$ with respect to sex differences and AD.

Keywords

APOE4, Alzheimer's Disease, Systems Genetics

Open Peer Review
Approval Status
$\begin{aligned} & \text { version 2 } \\ & \text { (revision) }\end{aligned}$
$\begin{aligned} & \text { 23 Jul 2019 } \\ & \text { version 1 } \\ & \text { 05 Apr 2019 }\end{aligned}$

1. J.Wesson Ashford, Stanford University, Stanford, USA

VA Palo Alto HCS, Livermore, USA

2. Yu-Wen Alvin Huang ID, Stanford

University, Stanford, USA

Bo Zhou ID, Stanford University, Stanford,

USA

Stanford University Medical School, Stanford, USA

Any reports and responses or comments on the article can be found at the end of the article. 
Corresponding author: Anna Delprato (adelprato@bioscienceproject.org)

Author roles: Hsu M: Conceptualization, Data Curation, Formal Analysis, Methodology, Writing - Original Draft Preparation, Writing Review \& Editing; Dedhia M: Data Curation, Formal Analysis, Writing - Original Draft Preparation, Writing - Review \& Editing; Crusio WE: Formal Analysis, Methodology, Writing - Review \& Editing; Delprato A: Conceptualization, Data Curation, Formal Analysis, Supervision, Writing - Original Draft Preparation, Writing - Review \& Editing

Competing interests: No competing interests were disclosed.

Grant information: The author(s) declared that no grants were involved in supporting this work.

Copyright: $\odot 2019$ Hsu M et al. This is an open access article distributed under the terms of the Creative Commons Attribution License, which permits unrestricted use, distribution, and reproduction in any medium, provided the original work is properly cited.

How to cite this article: Hsu M, Dedhia M, Crusio WE and Delprato A. Sex differences in gene expression patterns associated with the APOE4 allele [version 1; peer review: 1 approved, 1 approved with reservations] F1000Research 2019, 8:387

https://doi.org/10.12688/f1000research.18671.1

First published: 05 Apr 2019, 8:387 https://doi.org/10.12688/f1000research.18671.1 


\section{Introduction}

The APOE gene encodes the apolipoprotein E protein (ApoE), which associates with lipids to form lipoproteins that package and traffic cholesterol and lipids through the bloodstream (de Chaves \& Narayanaswami, 2008; Eichner et al., 2002; Puglielli et al., 2003). In the central nervous system, ApoE is primarily produced by astrocytes and carries cholesterol to neurons via ApoE receptors of the low-density lipoprotein receptor (LDLR) family (Getz \& Reardon, 2009; Holtzman et al., 2012). There are at least three different alleles of the $A P O E$ gene: $A P O E 2, A P O E 3$, and $A P O E 4$. In each of these variants, there are two distinct amino acid substitutions at positions 112 and 158 that alter the structure and function of the proteins (Ghebranious et al., 2005; Mahley et al., 2009).

Of the three alleles, APOE 3 is the most common and is believed to have a neutral role in Alzheimer disease (AD), whereas $A P O E 2$, the least common, is believed to have a protective role. The APOE4 polymorphism, which is found in around $20 \%$ of the population but $50 \%$ of all patients with $\mathrm{AD}$, increases an individual's risk for developing late-onset $\mathrm{AD}$ in a dosedependent manner (Ashford, 2004; Raber et al., 2004; van der Flier et al., 2006; Zuo et al., 2006).

Evidence suggests that the APOE4 allele may contribute to the risk of developing $\mathrm{AD}$ due to an increased amount of amyloid plaques in the brain tissue of affected individuals. In turn, a buildup of amyloid plaques may lead to neuronal degeneration and death, resulting in some of the symptoms associated with AD: memory loss, motor function impairment, dementia, and changes in personality (Barral et al., 2012; Deary et al., 2002; Kim et al., 2009).

Having the APOE4 mutation does not guarantee that a person will develop $\mathrm{AD}$, indicating that there are other genetic risk factors as well as environment and lifestyle elements that probably contribute to the etiology and progression of the disease.

Differences have been reported between females and males carrying the APOE4 allele. Women who are positive for APOE4 have a greater risk of developing $\mathrm{AD}$, show accelerated progression of the disease, and have more severe memory and cognitive decline than men with this allele (Altmann et al., 2014; Farrer et al., 1997). In a large scale meta-analysis that considered 58,000 research participants, it was also found that females with the APOE4 allele had a greater risk of developing $\mathrm{AD}$ earlier in life than males but that the sex difference was smaller than previously thought (Neu et al., 2017).

In this study, we examined gene expression patterns associated with aged female and male individuals who are positive for the APOE4 polymorphism in order to identify possible sex-related differences that may be relevant to the onset and progression of AD. Our hypothesis was that gene expression patterns based on correlation analysis with $A P O E$ expression in these individuals are different.

\section{Methods}

Data collection

The RNA sequence data used in this study is derived from the brains of an aged population obtained from the Aging, Dementia and Traumatic Brain Injury Study, accessed through the Allen Brain Atlas (http://aging.brain-map.org/). To obtain the data, a gene search specifying $A P O E$ was first performed. $A P O E$ was then selected and used to extract correlates for each brain region through drop down menus located on the same page. The drop-down menus allowed for the selection of brain region, APOE4-positive or -negative data, and sex. Once the selections were made, the "find correlates" button was used to retrieve the data. The datasets consist of gene expression data together with a clinical diagnosis comparison between males and females. The cohorts used in this study are as follows: APOE4-positive: female 7, males 13; and APOE4-negative: females 31, males 49.

\section{APOE gene correlates}

Genes whose expression correlated with that of the $A P O E$ gene were collected for the four available brain regions: frontal white matter (FWM) (associated with cognitive function, learning, dementia, and personality changes in AD), hippocampus (HIP), parietal cortex (PCx) (associated with sensory processing, attention, motor function, executive function, and spatial reasoning), and temporal cortex (TCx) (involved in sensory processing as well as declarative and long term memory). Data for each brain region was collected separately for all groups. For information about the RNA-sequence data generation and analysis, see the Quantitative Data Generation white paper in Documentation NA-Seq.

\section{Correlations evaluation}

Correlates to the $A P O E$ gene were obtained by querying the database and specifying these parameters: brain region, APOE4 positive and APOE4 negative, and sex. Correlations equal to or greater than $|0.7|$ were considered in the analysis. The rationale was to investigate genes with a similar expression pattern as $A P O E$ in these different groups to identify genes specific and common to each group, as well as possibly identify genes related to sex differences. Keyword search of the Database for Annotation, Visualization and Integrated Discovery (DAVID) version 6.8 (Huang da et al., 2009) table output was used to identify genes associated with biological processes related to $A P O E$, sex, and AD. Venny 2.0, an online program that compares lists of items, was used to determine the common and unique genes between groups, sex and brain regions.

\section{Statistical analysis}

Chi square analyses were used to compare the numbers of gene correlates between the APOE4-positive and APOE4-negative groups and between females and males (Microsoft Office Professional Plus, Excel 2013, Version 15).

\section{Gene expression sex differences}

The differential search function of the RNA-Seq page of the Allen Brain Database was used to find genes that show enrichment between females and males, and between males and females for 
each group and each brain region to identify sex related differences in gene expression patterns. Genes with a 1.5-fold difference expression and greater were evaluated.

\section{Gene Ontology characterization}

DAVID was used to obtain functional information based on Gene Ontology (GO) annotations for the gene correlates. Genes associated with a keyword search term related to $A P O E, \mathrm{AD}$, and sex were identified and noted.

\section{Pathway enrichment}

KEGG pathway enrichment (using DAVID) was used to further characterize the positive and negative APOE4 gene correlates for each group. Pathways were assessed manually and partitioned based on common themes.

\section{Results}

The APOE4 allele alters gene expression patterns

We observed a difference in transcription patterns associated with genes correlating with $A P O E$ expression in male and female individuals with the APOE4 allele as compared to APOE4-negative individuals. A difference in transcription patterns between APOE4-positive females and males was also observed.

As assessed by chi square analyses, the proportions of both positive and negative gene correlates to $A P O E$ larger than $|0.7|$ were significantly higher in all examined brain regions in both males and females in the APOE4-positive than in the APOE4negative groups (Extended data Workbooks 1 and 2; Delprato et al., 2019a; Delprato et al., 2019b).

Positive correlates: $A P O E 4$-positive vs APOE4-negative groups (all $\chi^{2}$ have 2 df and $\mathrm{p}<0.001$ ), females: FWM: $\chi^{2}=4470.1$; HIP: $\chi^{2}=1285.4$; PCx: $\chi^{2}=4050.4$; TCx: $\chi^{2}=3906.60$; males: FWM: $\chi^{2}=574.8$; HIP: $\chi^{2}=602.8 ; \mathrm{PCx}: \chi^{2}=187.4$; TCx: $\chi^{2}=318.5$.

Negative correlates: $A P O E 4$-positive vs APOE4-negative groups (all $\chi^{2}$ have $2 \mathrm{df}$ and $\mathrm{p}<0.001$ ), females: FWM: $\chi^{2}=2863.1$; HIP: $\chi^{2}=2654.5$; PCx: $\chi^{2}=2555.1$; TCx: $\chi^{2}=2335.1$; males: FWM: $\chi^{2}=470.8$; HIP: $\chi^{2}=351.4$; PCx: $\chi^{2}=220.3$; TCx: $\chi^{2}=671.1$.

In the APOE4-positive groups we also observed sex differences. Females carrying the APOE4-positive allele had significantly more gene correlates than APOE4-positive males. For all brain regions, differences between female and male groups in the numbers of correlates obtained at or above the cutoff value $(r=>|0.7|)$ were assessed with chi square tests $(2 \times 2, d f=2)$.

Positive correlates: males $v s$ females (all $\chi^{2}$ have 2 df and $\mathrm{p}<0.001$ ): FWM: $\chi^{2}=1926.7 ; \quad$ HIP: $\chi^{2}=237.9 ; \quad$ PCx: $\chi^{2}=2693.4 ;$ TCx: $\chi^{2}=2565.1$.

Negative correlates: males $v s$ females (all $\chi^{2}$ have $2 \mathrm{df}$ and p<0.001): FWM: $\chi^{2}=1051.8$; HIP: $\chi^{2}=1660.9$; PCx: $\chi^{2}=2125.8$; TCx: $\chi^{2}=826.0$.
In the APOE4-negative groups, sex differences were also observed, but they were less strong than in the APOE4 positive groups. For the positive correlates, females had significantly more gene correlates than males. However, for the negative correlates, this was reversed for the FWM, whereas no differences were found for the HIP and TCx.

Positive correlates: males vs females (all $\chi^{2}$ have $2 \mathrm{df}$ and $\mathrm{p}<0.001$ unless indicated otherwise): FWM: $\chi^{2}=73.6$; HIP: $\chi^{2}=5.3(0.10>\mathrm{p}>0.05)$; PCx: $\chi^{2}=6.5(\mathrm{p}<0.05)$; TCx: $\chi^{2}=21.8$.

Negative correlates: males vs females (all $\chi^{2}$ have $2 \mathrm{df}$ and $\mathrm{p}<0.001$ unless indicated otherwise): FWM: $\chi^{2}=150.0$; HIP: $\chi^{2}=3.0$ (ns); PCx: $\chi^{2}=84.1$; TCx: $\chi^{2}=0.9$ (ns).

The results indicate that for all brain regions and for both sexes, the number of $A P O E$ correlates, and therefore gene expression patterns, are significantly different between the groups carrying the APOE4 allele as compared to APOE4-negative individuals and that expression patterns also differ between females and males of the APOE4-positive groups.

\section{Common and unique genes}

For the common gene correlates to $A P O E$ in $A P O E 4$-positive and $A P O E 4$-negative individuals, the results for the female and male comparison are as follows: TCx: $47 / 37$ (positive/negative) common genes between females and males, 3263/2532 genes unique to females, 420/577 genes unique to males; HIP 22/16 common genes between females and males, 1164/1984 genes unique to females, 544/323 genes unique to males; FWM 48/22 common gene between females and males, 3465/2335 genes unique to females, 952/818 genes unique to males; PCx 54/42 common gene between females and males, 3432/2605 genes unique to females, 213/175 genes unique to males (Extended data Workbook 3; Delprato et al., 2019c).

\section{GO enrichment}

Results from a keyword search of GO terms obtained for positive and negative gene correlates for both the APOE4positive and APOE4-negative male and female groups across the four brain regions show the same trend of enrichment (Figure 1 and Extended data Workbook 4; (Delprato et al., 2019d). Several of the keywords used to analyze the correlates, were associated with a greater number of genes in each brain region and for both positive and negative correlates. The keyword categories are: "immune", "oxidation", "inflammation", "lipid metabolism", "hormone", and "insulin". Despite the common categories between females and males, there are very few common genes (Extended data Workbook 4; Delprato et al., 2019d).

For the keyword categories, there were no common genes between males and females in the FWM correlates, For the other brain regions common genes between males and females are as follows: HIP positive correlates: "inflammation", CD4 and CXCL1; negative correlates PPP1CC; PCx negative correlates 
A
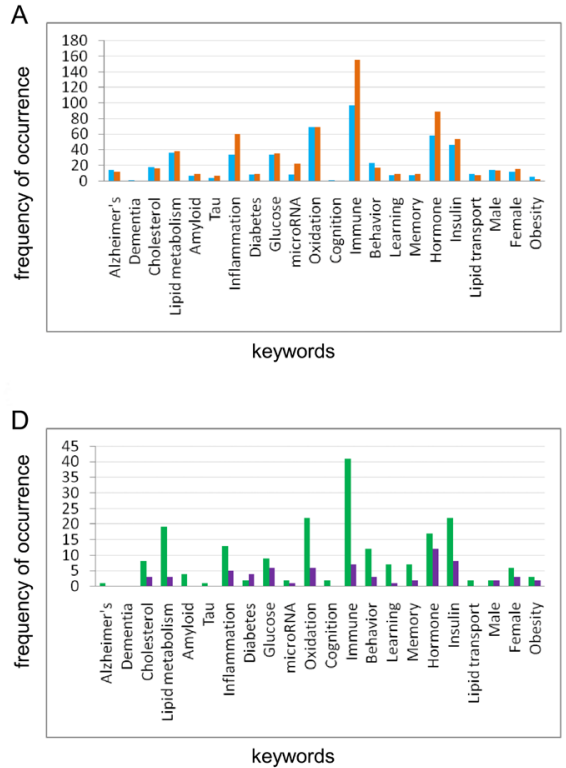

B

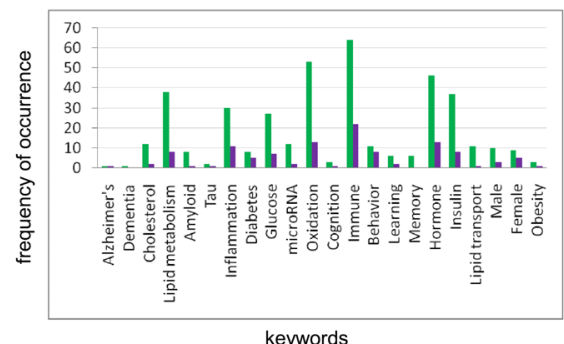

E

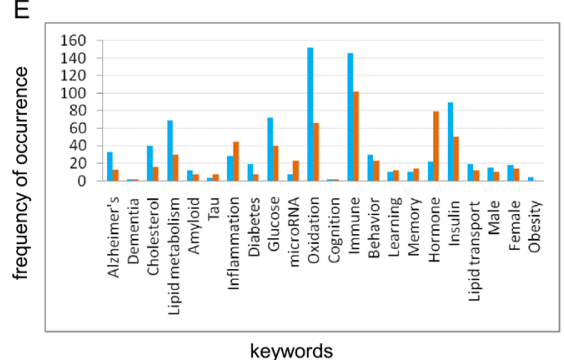

C

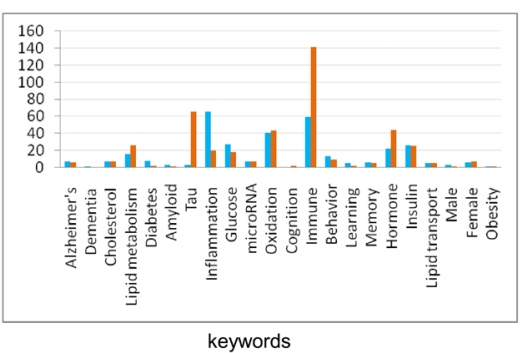

keywords

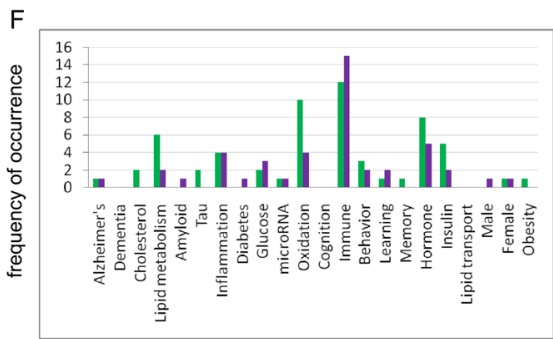

keywords
G

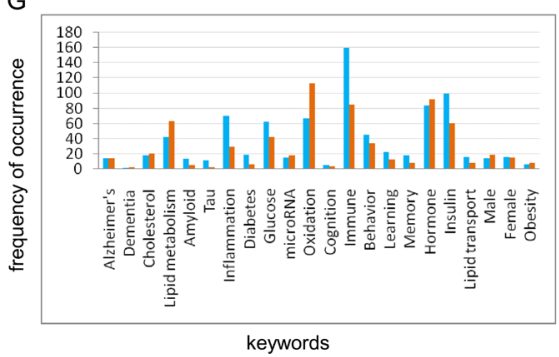

$\mathrm{H}$

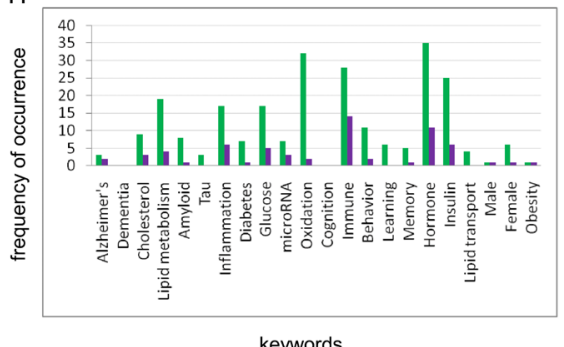

Figure 1. Keyword enrichment. Representative keyword enrichment based on GO Term classification. (A) Females and (B) males, frontal white matter; (C) females and (D) males, hippocampus; (E) females and (F) males, parietal cortex; (G) females and (H) males, temporal cortex. X-axis, keyword categories; Y-axis, frequency of occurrence.

"Lipid metabolism" PTGES3; "Inflammation" PTGER4; "Oxidation" MTHFD2L; "Immune", FSD1L, PTGER4; "Hormone" PGRMC2; TCx negative correlates "Inflammation" TBC1D23; "Hormone" GNRH1.

Whether either of the female or male groups had more of any one type of gene is not clear, due to the greater number of gene correlates observed for females. In this respect, the female groups generally had more genes in each of these keyword categories overall. The females also have a substantial number of Alzheimer-related genes associated with each brain region (Extended data Workbook 4; Delprato et al., 2019d).

\section{Pathway enrichment}

Female pathways. To gain further insight into the function of the gene correlates, a pathway analysis was performed for each group (Figure 2 and Extended data Workbook 5; Delprato et al., 2019e). For APOE4-positive females, the strongest pathway themes, when combined, are associated with various types of signaling cascades, such as MAPK (cell cycle, transcription, stress response), Chemokine (immune response), cAMP (2nd messenger signaling), Jak-STAT (immune function, cell division, apoptosis, TNF( immune system function, inflammation, infection response, apoptosis), Toll-like receptor (immune function, innate immunity), neurotrophin (growth factors, protection, development and function of neurons), VEGF (growth factors, vascularization, cancer), hedgehog (cell differentiation and cancer), infection, immune system processes, amino acid metabolism, lipid metabolism, energy metabolism, RNA related processes, cancer, trafficking and recycling organelles (endosome, lysosome, peroxisome).

The PCx-positive correlates are associated with the AD, Parkinson, and Huntington pathways. There are 16 genes (ATP5D, ATP6, ATP8, COX1, COX2, COX3, COX6A2, CYTB, NDUFA1, NDUFA13, NDUFA4L2, NDUFB7, NDUFS6, NDUFS7, NDUFS8, $U Q C R 11)$ in common among these pathways and all are related to energy production, mitochondria related-electron transport and oxidative phosphorylation.

Five genes from the HIP negative correlates associated with the Prion disease pathway: $C 1 Q A, C 7, C 1 Q B, C 6$ and $C 1 Q C$; these are all related to the complement pathway of the innate immune system. 


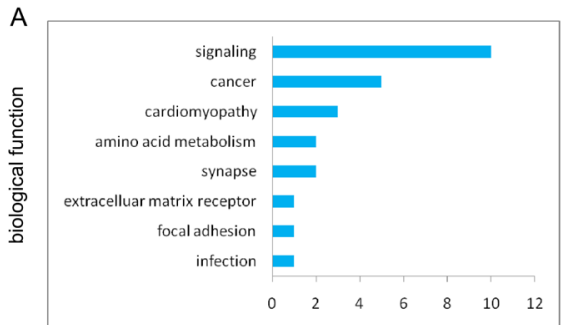

frequency of occurrence

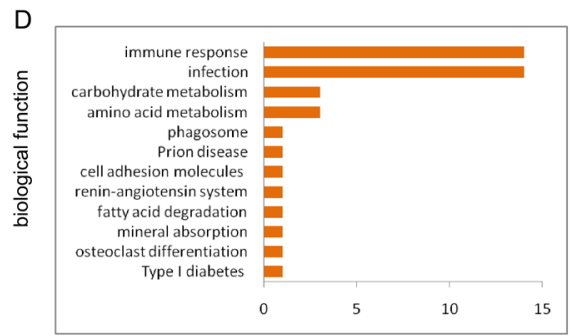

frequency of occurrence

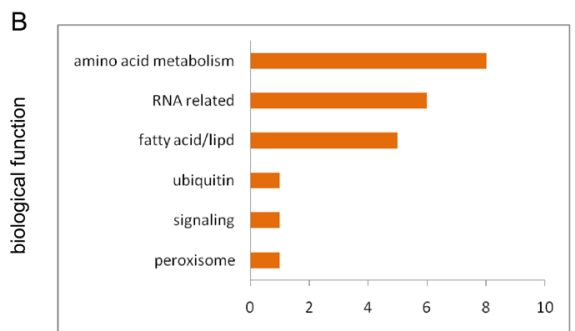

frequency of occurrence

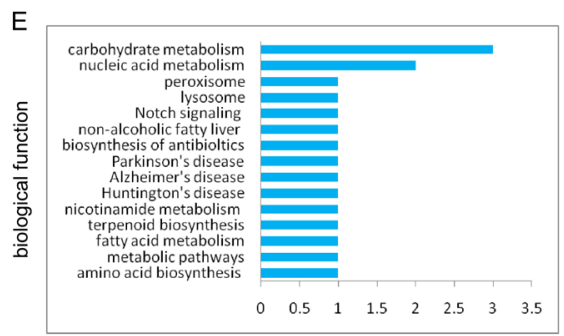

frequency of occurrence

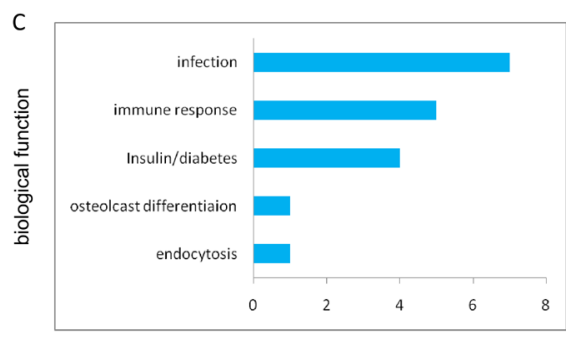

frequency of occurrence

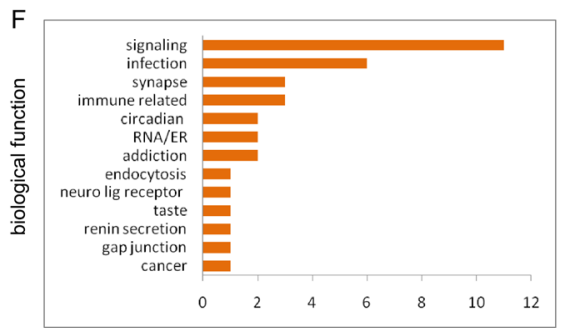

frequency of occurrence

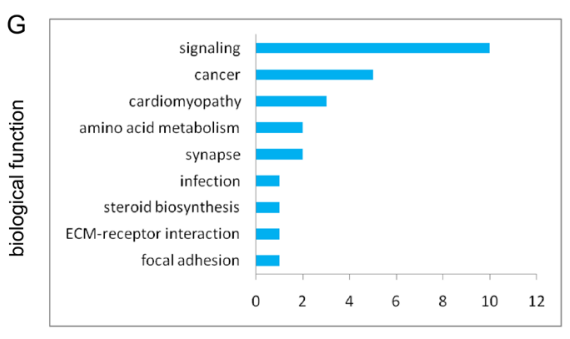

frequency of occurrence

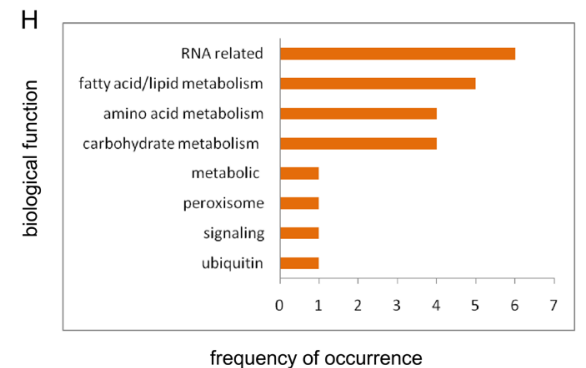

Figure 2. Pathway enrichment. KEGG pathway categories for female gene correlates. (A) Positive correlates and (B) negative correlates, frontal white matter; $(\mathbf{C})$ positive correlates and $(\mathbf{D})$ negative correlates, hippocampus; (E) positive correlates and $(\mathbf{F})$ negative correlates; parietal cortex; $(\mathbf{G})$ positive correlates and $(\mathbf{G})$ negative correlates, temporal cortex. X-axis, frequency of occurrence; Y-axis, biological function.

Male pathways. For males, the overall number of pathways associated with the APOE4-positive gene correlates were much fewer than for the females, and in some cases, such as for the $\mathrm{PCX}$-positive correlates and TCX-negative correlates, there were no pathways identified. The greatest number of pathways for males were obtained for the TCx-positive correlates and these were related to fatty acid metabolism, amino acid biosynthesis, cell attachment/cytoskeleton, neuro-related processes such as GABA axon guidance, viral infection, immune function. The HIP positive correlates were related to fatty acid metabolism, amino acid metabolism, Lupus, and viral carcinogenesis. For the HIPnegative correlates two pathways were obtained: alcoholism and RNA transport. For the PCx-negative correlates there were four pathways: spliceosome, RNA degradation, NF- $\kappa \beta$ signaling and pertussis. For the other brain regions in males there was one pathway for both positive and negative correlates associated with the FWM: Fatty acid/lipid, carbohydrate metabolism, degradation and glycosphingolipid biosynthesis-lacto and neolacto series (Extended data Workbook 5; Delprato et al., 2019e).

\section{Comparison of female and male pathways}

Pathways that were exactly the same between female and males were found for the TCx region only, and these are: hsa04510: Focal adhesion, hsa04512:ECM-receptor interaction, hsa05412: Arrhythmogenic right ventricular cardiomyopathy hsa05410: Hypertrophic cardiomyopathy, hsa05414:Dilated cardiomyopathy, hsa04724:Glutamatergic synapse, and hsa00330:Arginine and Proline metabolism.

For the other brain regions, some of the associated pathways were similar in biological function. Common themes between females and males were related to fatty acid, processes, cardiomyopathy, energy metabolism, amino acid metabolism, cell attachment, ECM (extracellular matrix) receptor interaction, glutamatergic synapse, and pathways related to immune function.

Several themes associated with the APOE4-positive females stand out as being distinct from males' pathways and these are related to cancer, signaling, RNA processes, and a myriad of bacterial, viral, and parasitic infectious disease pathways, which include 
components of endocytosis, intracellular traffic, and immune system function.

Differential gene expression between females and males in APOE4-positive and APOE4-negative groups

Genes expressed higher in females. For all groups and for each brain region in the female and male comparison there is one gene, XIST, associated with $\mathrm{X}$ chromosome inactivation, that is highly expressed and female specific (Ji et al., 2015). For the APOE4-positive group and for each brain region there are several genes that have higher expression values for females over males. Seven of these genes are heat shock proteins, which are involved in the cellular stress response, and chaperones, which assist in protein folding and unfolding: BAG3, DNAJB1, CRYAB1, HSPA1A, HSPA1B, HSPA6, HSPB1. The two highest expressed genes aside from XIST are HSPA1A and HSPA1B. The latter two are present in female datasets but not in males. The other top expressing genes in the female and male comparison are RPL9, which is down regulated in severe AD (Kong et al. 2009) and RNU5E-1, small nuclear RNA (Figure 3 and Extended data Workbook 6; Delprato et al., 2019f).

Genes expressed higher in males. For all groups and brain regions, the same top gene, RPS4Y1, which is on the $\mathrm{Y}$ chromosome and encodes for the 40S ribosomal subunit, is highly expressed. RPS4Y1 is an RNA binding protein and it is involved in rRNA processing, translation, and protein targeting. Several other genes are expressed at high levels in males. These include KDM5D (immune system function, oxidation reduction, T-cell antigen processing and presentation, regulation of androgen receptor signaling pathway), USP9Y (ubiquitin/deubiquitination), SNORD3B-2/1 small nuclear RNAs (RNA biogenesis/transport), TXLNGY (syntaxin binding, taxin family), ZFY (transcription regulation), NLGN4Y (lipid metabolism, synapse assembly, neuron cell-cell adhesion), $D D X 3 Y$ (regulation of gene expression, RNA helicase). With the exception of $S N O R D 3 B-2 / 1$, all of the other genes are linked to the $\mathrm{Y}$ chromosome and are male specific. Other male genes expressed at lower levels but above the cutoff value have diverse functions, including splicing, immune response, and ubiquitination. Based on GO term annotation, none of the top expressing genes in the male and female comparison are heat shock or chaperone proteins but there is one chaperone protein in males just expressed at a 2.0-fold difference, $\mathrm{HBB}$, which is specific for hemoglobin (Figure 3, Extended data Workbook 6; Delprato et al., 2019f).

We also examined the differential gene expression pattern of transcription factors associated with APOE4-positive and
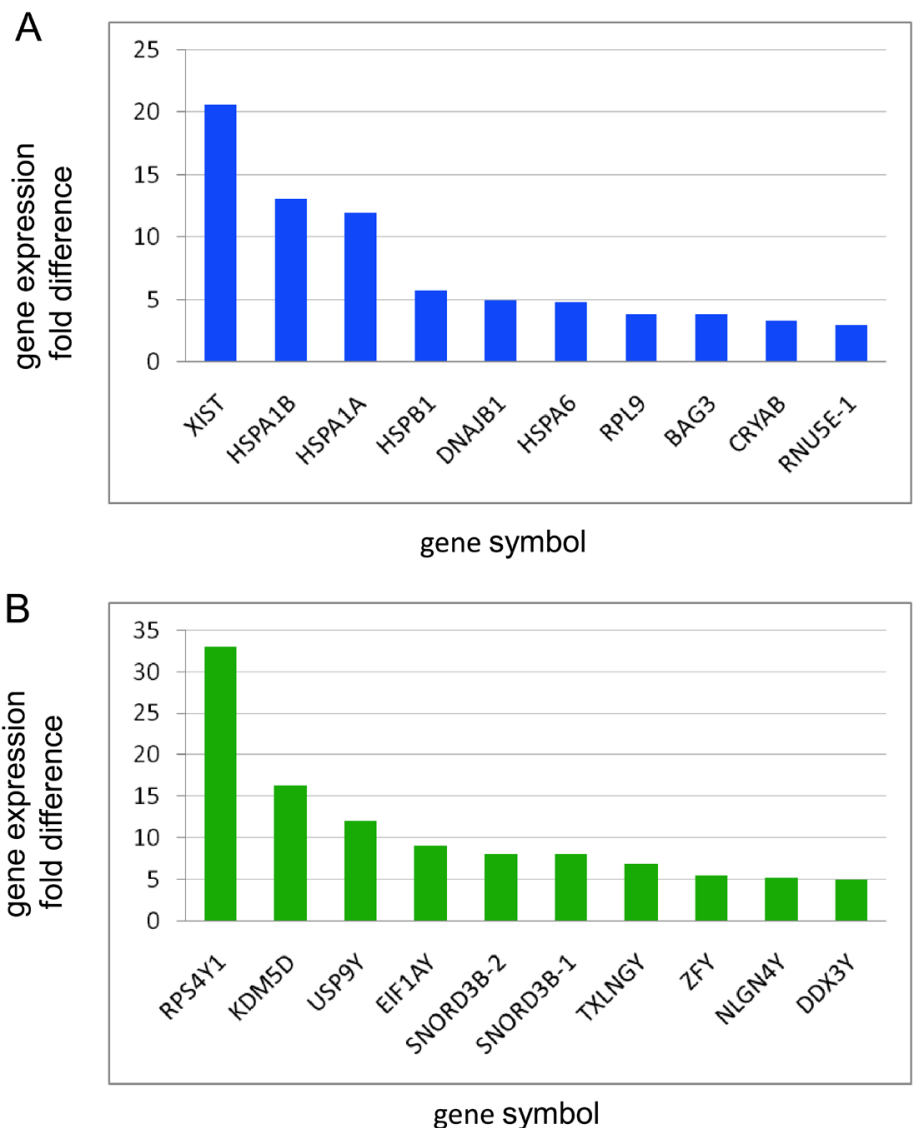

Figure 3. Sex differences in gene expression. (A) Top differentially expressed genes in the frontal white matter of APOE4-positive females and (B) representative top genes differentially expressed in APOE4-positive males. X-axis, gene symbol; Y-axis, fold difference values. 
APOE4-negative individuals and we observed distinct expression of transcription factors between these groups and also between females and males (Extended data Workbook 7; Delprato et al., 2019g).

There are an increased number of transcription factors expressed in APOE4-positive females as compared with APOE4-positive males. This is also the case for APOE4-positive females as compared to the APOE4-negative female group. For males, the APOE4-negative and APOE4-positive groups have more or less the same set of transcription factors expressed in each brain region with the exception of the FWM in the APOE4-negative group.

Transcription factors overexpressed in females as compared to males for $A P O E 4$-positive groups by brain region are as follows. FWM: FOS, JUN, JUNB, S100A8, A100A9, ATF3, HSPA1A, HSPA1B, HMOX1, IL1B, NPAS4, SIK1, ZSCAN31, HIP, FOS, JUNB, S100A12, NME1-NME2, S100A8, S100A9, ATF3, HSPA1A, HSPA1B, HMOX1, NR4A1, VEGFA; PCx; FOS, FOSB, JUNB, NKX6-2, S100A8, S100A9, ATF3, HSPA1A, HSPA1B, ID3 NR4A1, NR4A2, SIK1; TCX: S100A12, S100A9, HSPA1A, HSPA1B.

For APOE4-negative females, there were no differentially expressed transcription factors observed for the FWM, PCx, and TCx. The exception was for the HIP where HSPAlA and $H S P A 1 B$ were expressed above the threshold value of 1.5 -fold difference.

In males there are generally the same set of transcription factors for APOE4-positive and APOE4-negative groups associated with the HIP, PCx, and TCx, and three of these are $\mathrm{Y}$ chromosome specific: $K D M 5 D, Z F Y$, and $H S F Y 1$.

An exception was observed for the male APOE4-negative group. Associated with the FWM, there were several additional transcription factors expressed above the threshold value (FOS, CAPN3, ENPP2, GREM1, KDM5D, VEGFA, ZFY and two of these, FOS and VEGFA, also occur in the female APOE4-positive groups (FOS: FWM, HIP, PCx; VEGFA: HIP). Otherwise, the expression of transcription factors observed between females and males is distinct.

\section{Discussion}

The APOE4 allele is the most significant genetic risk factor for late onset AD (Corder et al., 1993; Neu et al., 2017; Raber et al., 2004). It is also associated with aging, atherosclerosis, Lewy Body Dementia, and cardiovascular disease (de Chaves \& Narayanaswami 2008; Dickson et al., 2018; Eichner et al., 2002; Riedel et al., 2016). In this study we used a correlation analysis approach to examine gene expression patterns in an aged population consisting of APOE4-positive and APOE4-negative women and men. The goal of this study was to possibly identify sex-related differences in individuals carrying the APOE4 allele. This is because many studies have reported differences in the effects of the APOE4 allele on females particularly, in the context of $\mathrm{AD}$ with respect to age of onset and accelerated disease progression associated with dementia and cognitive decline (Farrer et al., 1997; Podcasy \& Epperson, 2016; Riedel et al., 2016; Vest \& Pike, 2013). Our hypothesis was that gene expression patterns in APOE4-positive and APOE4-negative individuals would differ. We found a large number of genes with the same expression pattern as $A P O E$ in APOE4-positive, but not APOE4-negative individuals. This trend was larger in APOE4-positive females as compared with APOE4-positive males and with $A P O E 4$-negative control groups.

We did not anticipate that such a large number of gene correlates observed within the significance range would differ between the APOE4-positive and APOE4-negative groups and also between $A P O E 4$-positive females and males, even though the expectation had been that there would be differences related to gene function. Despite the differences in the overall numbers of correlates between the groups, the same major categories of genes were observed for both positive and negative correlates as well as for all of the four brain regions considered in this study. The categories of genes relate to immune processes, oxidation, inflammation, lipid metabolism, and hormones.

The results are largely consistent with what is known about $A P O E$ function. It is interesting, but in retrospect not surprising, that the same gene categories would emerge for all groups despite the substantial differences in the numbers of gene correlates which may be associated with the different biological processes affected by the APOE4 allele.

The results of the pathway analysis were somewhat similar, but some differences were also observed. A large number of pathways were obtained for the female gene correlates, but many fewer for the males, which is not surprising given the larger number of gene correlates for females. Those that could be compared between the two sexes show that there are common themes such as immune function, lipid metabolism, and inflammation. Interestingly, many of the female pathways were related to microbial infection, major signalling circuits, and amino acid metabolism. Several other pathways were concerned with RNA, cancer, and cardiovascular processes. These are very diverse but all relatable to $A P O E$ function and biological programs.

In the evaluation of genes expressed at higher levels in APOE4-positive females than in males, several genes were observed exclusively in females; these were either chaperones that function in protein folding and unfolding or heat shock proteins that play a protective role in cellular stress. The role of these proteins in AD has been investigated (Campanella et al., 2018; Hamos et al., 1991; Marino Gammazza et al., 2016). In contrast, the genes expressed higher in males than in females were Y-chromosome specific. Distinct patterns of transcription factor expression were also observed between the groups. The transcription factors that are expressed in APOE4-positive females are involved in the regulation of a multitude of diverse processes. Several of these have established roles in the regulation of immune system response, inflammation, oxidative stress, aging, and estrogen signaling, which may be of 
particular relevance to this study (Extended data Workbook 7; Delprato et al., 2019g).

Others have reported differences in gene expression patterns associated with the APOE4 allele (Huang et al., 2017; Lin et al., 2018; Theendakara et al., 2018). The APOE4 allele has also been shown to alter the transcriptional profile of 857 genes with similar expression patterns to $A P O E$ in induced neurons and glia (Lin et al., 2018). The major pathways identified for these genes are consistent with what we observe: lipid processes, immune system, inflammation, energy metabolism, and transcription. There is a growing body of evidence indicating that $A P O E$ has transcription factor activity. Most of the studies in support of this were done in vitro and in mouse models. Further testing in humans is imperative and may provide a clearer understanding of the relationship between $A P O E$, aging, and AD.

The results from our study are consistent with known $A P O E$ related processes and provide further support for the regulatory role of $A P O E$ as a transcription factor. That our findings are consistent with other reports that have used different models to study the relationship of $A P O E$ with $\mathrm{AD}$ and aging support the approach that we have taken (Huang et al., 2017; Lin et al., 2018; Theendakara et al., 2018). We provide further relevance and insight for the differential transcription-related effects of the APOE4 allele in APOE4-positive males and females, which may be related to the overall heightened immune response and increased risk for AD observed in females (Klein, 2012; Taneja, 2018). The identification of specific genes, gene families, and pathways that are affected by the APOE4 allele will help to dissect its complex role in diverse but interrelated physiological processes. It would be interesting to compare the results from our study with APOE4 expression patterns in a younger population to see if these differences between APOE4-positive and -negative groups and between females and males are already present and detectable early on or are age dependent.

\section{Data availability}

Underlying data

Underlying RNA sequence data used in this study was obtained from the Aging, Dementia and Traumatic Brain Injury Study, accessed through the Allen Brain Atlas (http://aging.brain-map. $\operatorname{org} /)$.

\section{Extended data}

Figshare: Workbook 1. Positive and negative gene correlates for APOE4+ and APOE4- females. Frontal white matter, Hippocampus, Parietal cortex, and Temporal cortex. https://doi.org/10.6084/ m9.figshare.7849175 (Delprato et al., 2019a)

Workbook 2. Positive and negative gene correlates for APOE4+ and APOE4- males. Frontal white matter, Hippocampus, Parietal cortex, and Temporal cortex. https://doi.org/10.6084/ m9.figshare.7849190 (Delprato et al., 2019b)

Workbook 3. Common and unique genes for APOE4+ and APOE4- males and females. Frontal white matter, Hippocampus, Parietal cortex, Temporal cortex https://doi.org/10.6084/ m9.figshare.7849196 (Delprato et al., 2019c)

Workbook 4. Keywords for gene correlates APOE4+ and APOE4- females and males. Frontal white matter, Hippocampus, Parietal cortex, Temporal cortex https://doi.org/10.6084/ m9.figshare.7849214 (Delprato et al., 2019d)

Workbook 5. KEGG Pathways for positive and negative correlates associated with APOE4+ and females and males. Frontal white matter, Hippocampus, Parietal cortex, Temporal cortex https://doi.org/10.6084/m9.figshare.7849229 (Delprato et al., 2019e)

Workbook 6. Differential gene expression in APOE4+ and APOE4- females and males. Frontal white matter, Hippocampus, Parietal cortex, Temporal cortex https://doi.org/10.6084/ m9.figshare.7849238 (Delprato et al., 2019f)

Workbook 7. Differentially expressed transcription factors in females and males. GO Biological Process. Frontal white matter, Hippocampus, Parietal cortex, Temporal cortex https://doi. org/10.6084/m9.figshare.7849253 (Delprato et al., 2019g)

Extended data are available under the terms of the Creative Commons Zero "No rights reserved" data waiver (CC0 1.0 Public domain dedication).

Grant information

The author(s) declared that no grants were involved in supporting this work.
Altmann A, Tian L, Henderson VW, et al.: Sex modifies the APOE-related risk of developing Alzheimer disease. Ann Neurol. 2014; 75(4): 563-573. PubMed Abstract | Publisher Full Text | Free Full Text

Ashford JW: APOE genotype effects on Alzheimer's disease onset and epidemiology. J Mol Neurosci. 2004; 23(3): 157-165. PubMed Abstract | Publisher Full Text

Barral S, Bird T, Goate A, et al.: Genotype patterns at PICALM, CR1, BIN1, CLU, and APOE genes are associated with episodic memory. Neurology. 2012; 78(19): 1464-1471.

PubMed Abstract | Publisher Full Text | Free Full Text
Campanella C, Pace A, Caruso Bavisotto C, et al.: Heat Shock Proteins in Alzheimer's Disease: Role and Targeting. Int J Mol Sci. 2018; 19(9): pii: E2603. PubMed Abstract | Publisher Full Text | Free Full Text

Corder EH, Saunders AM, Strittmatter WJ, et al:: Gene dose of apolipoprotein E type 4 allele and the risk of Alzheimer's disease in late onset families. Science. 1993; 261(5123): 921-923.

PubMed Abstract | Publisher Full Text

de Chaves EP, Narayanaswami V: Apolipoprotein E and cholesterol in aging and disease in the brain. Future Lipidol. 2008; 3(5): 505-530. PubMed Abstract | Free Full Text 
Deary IJ, Whiteman MC, Pattie A, et al:: Cognitive change and the APOE epsilon 4 allele. Nature. 2002; 418(6901): 932.

PubMed Abstract | Publisher Full Text

Delprato A, Crusio W, Dedhia M, et al:: Workbook 1. Positive and negative gene correlates for APOE4+ and APOE4- females. Frontal white matter, Hippocampus, Parietal cortex, and Temporal cortex. figshare. Fileset. 2019a. http://www.doi.org/10.6084/m9.figshare.7849175.v1

Delprato A, Crusio W, Dedhia M, et al.: Workbook 2. Positive and negative gene correlates for APOE4+ and APOE4- males. Frontal white matter, Hippocampus, Parietal cortex, and Temporal cortex. figshare. Fileset. 2019b.

http://www.doi.org/10.6084/m9.figshare.7849190.v1

Delprato A, Crusio W, Dedhia M, et al:: Workbook 3. Common and unique genes for APOE4+ and APOE4- males and females. Frontal white matter, Hippocampus, Parietal cortex, Temporal cortex. figshare. Fileset. 2019c. http://www.doi.org/10.6084/m9.figshare.7849196.v1

Delprato A, Crusio W, Dedhia M, et al:: Workbook 4. Keywords for gene correlates APOE4+ and APOE4- females and males. Frontal white matter, Hippocampus, Parietal cortex, Temporal cortex. figshare. Fileset. 2019d. http://www.doi.org/10.6084/m9.figshare.7849214.v1

Delprato A, Crusio W, Dedhia M, et al.: Workbook 5. KEGG Pathways for positive and negative correlates associated with APOE4+ females and males. Frontal white matter, Hippocampus, Parietal cortex, Temporal cortex. figshare. Fileset. 2019 e.

http://www.doi.org/10.6084/m9.figshare.7849229.v2

Delprato A, Crusio W, Dedhia M, et al.: Workbook 6. Differential gene expression in APOE4+ and APOE4- females and males. Frontal white matter, Hippocampus, Parietal cortex, Temporal cortex. figshare. Fileset. $2019 \mathrm{f}$. http://www.doi.org/10.6084/m9.figshare.7849238.v1

Delprato A, Crusio W, Dedhia M, et al:: Workbook 7. Differentially expressed transcription factors in females and males.GO Biological Process. Frontal white matter, Hippocampus, Parietal cortex, Temporal cortex. figshare. Fileset. $2019 \mathrm{~g}$.

http://www.doi.org/10.6084/m9.figshare.7849253.v2

Dickson DW, Heckman MG, Murray ME, et al:: APOE $\varepsilon 4$ is associated with severity of Lewy body pathology independent of Alzheimer pathology. Neurology. 2018; 91(12): e1182-e1195.

PubMed Abstract | Publisher Full Text | Free Full Text

Eichner JE, Dunn ST, Perveen G, et al:: Apolipoprotein E polymorphism and cardiovascular disease: a HuGE review. Am J Epidemiol. 2002; 155(6): 487-495. PubMed Abstract | Publisher Full Text

Farrer LA, Cupples LA, Haines JL, et al.: Effects of age, sex, and ethnicity on the association between apolipoprotein E genotype and Alzheimer disease. A meta-analysis. APOE and Alzheimer Disease Meta Analysis Consortium. JAMA. 1997; 278(16): 1349-1356.

PubMed Abstract | Publisher Full Text

Getz GS, Reardon CA: Apoprotein E as a lipid transport and signaling protein in the blood, liver, and artery wall. J Lipid Res. 2009; 50 Suppl: S156-61. PubMed Abstract | Publisher Full Text | Free Full Text

Ghebranious N, Ivacic L, Mallum J, et al.: Detection of ApoE E2, E3 and E4 alleles using MALDI-TOF mass spectrometry and the homogeneous mass-extend technology. Nucleic Acids Res. 2005; 33(17): e149. PubMed Abstract | Publisher Full Text | Free Full Text

Hamos JE, Oblas B, Pulaski-Salo D, et al.: Expression of heat shock proteins in Alzheimer's disease. Neurology. 1991; 41(3): 345-350.

PubMed Abstract | Publisher Full Text

Holtzman DM, Herz J, Bu G: Apolipoprotein E and apolipoprotein E receptors: normal biology and roles in Alzheimer disease. Cold Spring Harb Perspect Med. 2012; 2(3): a006312.

PubMed Abstract | Publisher Full Text | Free Full Text

Huang da W, Sherman BT, Lempicki RA: Systematic and integrative analysis of large gene lists using DAVID bioinformatics resources. Nat Protoc. 2009; 4(1): $44-57$.

PubMed Abstract | Publisher Full Text
Huang YA, Zhou B, Wernig M, et al.: ApoE2, ApoE3, and ApoE4 Differentially Stimulate APP Transcription and A $\beta$ Secretion. Cell. 2017; 168(3): 427-441.e21.

PubMed Abstract | Publisher Full Text | Free Full Text

Ji B, Higa KK, Kelsoe JR, et al:: Over-expression of XIST, the Master Gene for $X$ Chromosome Inactivation, in Females With Major Affective Disorders. EBioMedicine. 2015; 2(8): 909-918.

PubMed Abstract | Publisher Full Text | Free Full Text

Kim J, Basak JM, Holtzman DM: The role of apolipoprotein E in Alzheimer's disease. Neuron. 2009; 63(3): 287-303

PubMed Abstract | Publisher Full Text | Free Full Text

Klein SL: Sex influences immune responses to viruses, and efficacy of prophylaxis and treatments for viral diseases. BioEssays. 2012; 34(12): 1050-1059.

PubMed Abstract | Publisher Full Text | Free Full Text

Kong W, Mou X, Liu Q, et al: Independent component analysis of Alzheimer's DNA microarray gene expression data. Mol Neurodegener. 2009; 4: 5.

PubMed Abstract | Publisher Full Text | Free Full Text

Lin YT, Seo J, Gao F, et al:: APOE4 Causes Widespread Molecular and Cellular Alterations Associated with Alzheimer's Disease Phenotypes in Human iPSCDerived Brain Cell Types. Neuron. 2018; 98(6): 1141-1154.e7.

PubMed Abstract | Publisher Full Text | Free Full Text

Mahley RW, Weisgraber KH, Huang Y: Apolipoprotein E: structure determines function, from atherosclerosis to Alzheimer's disease to AIDS. $J$ Lipid Res. 2009; 50 Suppl: S183-8.

PubMed Abstract | Publisher Full Text | Free Full Text

Marino Gammazza A, Bavisotto CC, Barone R, et al.: Alzheimer's Disease and Molecular Chaperones: Current Knowledge and the Future of

Chaperonotherapy. Curr Pharm Des. 2016; 22(26): 4040-4049.

PubMed Abstract | Publisher Full Text

Neu SC, Pa J, Kukull W, et al:: Apolipoprotein E Genotype and Sex Risk Factors for Alzheimer Disease: A Meta-analysis. JAMA Neurol. 2017; 74(10): 1178-1189. PubMed Abstract | Publisher Full Text | Free Full Text

Podcasy JL, Epperson CN: Considering sex and gender in Alzheimer disease and other dementias. Dialogues Clin Neurosci. 2016; 18(4): 437-446. PubMed Abstract | Free Full Text

Puglielli L, Tanzi RE, Kovacs DM: Alzheimer's disease: the cholestero connection. Nat Neurosci. 2003; 6(4): 345-351.

PubMed Abstract | Publisher Full Text

Raber J, Huang Y, Ashford JW: ApoE genotype accounts for the vast majority of AD risk and AD pathology. Neurobiol Aging. 2004; 25(5): 641-650.

PubMed Abstract | Publisher Full Text

Riedel BC, Thompson PM, Brinton RD: Age, APOE and sex: Triad of risk of Alzheimer's disease. J Steroid Biochem Mol Biol. 2016; 160: 134-147.

PubMed Abstract | Publisher Full Text | Free Full Text

Taneja V: Sex Hormones Determine Immune Response. Front immunol. 2018; 9: 1931.

PubMed Abstract | Publisher Full Text | Free Full Text

Theendakara V, Peters-Libeu CA, Bredesen DE, et al:: Transcriptional Effects of ApoE4: Relevance to Alzheimer's Disease. Mol Neurobiol. 2018; 55(6): 5243-5254.

PubMed Abstract | Publisher Full Text

van der Flier WM, Schoonenboom SN, Pijnenburg YA, et al:: The effect of APOE genotype on clinical phenotype in Alzheimer disease. Neurology. 2006; 67(3): 526-527.

PubMed Abstract | Publisher Full Text

Vest RS, Pike CJ: Gender, sex steroid hormones, and Alzheimer's disease.

Horm Behav. 2013; 63(2): 301-7.

PubMed Abstract | Publisher Full Text | Free Full Text

Zuo L, van Dyck CH, Luo X, et al:: Variation at APOE and STH loci and

Alzheimer's disease. Behav Brain Funct. 2006. 2. 13.

PubMed Abstract | Publisher Full Text | Free Full Text 


\section{Open Peer Review}

\section{Current Peer Review Status:}

\section{Version 1}

Reviewer Report 17 May 2019

https://doi.org/10.5256/f1000research.20445.r47508

(c) 2019 Huang $Y$ et al. This is an open access peer review report distributed under the terms of the Creative Commons Attribution License, which permits unrestricted use, distribution, and reproduction in any medium, provided the original work is properly cited.

\section{Yu-Wen Alvin Huang}

Department of Molecular and Cellular Physiology, Howard Hughes Medical Institute, Stanford Medical School, Stanford University, Stanford, CA, USA

\section{Bo Zhou}

1 Department of Molecular and Cellular Physiology, Howard Hughes Medical Institute, Stanford Medical School, Stanford University, Stanford, CA, USA

2 Institute for Stem Cell Biology and Regenerative Medicine and Department of Pathology, Stanford University Medical School, Stanford, CA, USA

The allelic variant of apolipoprotein $\mathrm{E}$ (ApoE) gene, APOE-e4, is the strongest genetic risk factor for Alzheimer's disease (AD), with a clearly greater female than male predisposition (reviewed in Belloy et al., $2019^{1}$ ). Despite the prominence and significance of this APOE-by-sex interaction, the underlying mechanism remains to be elucidated. To tackle this critical issue in a comprehensive fashion, Hsu et al. mined the rich data sets of The Aging, Dementia and Traumatic Brain Injury Study, which comprise structured information including transcriptomics, clinical and pathological findings based on 107 aged brains (http://aging.brain-map.org/). Their functional analyses of genes correlating to APOE expression support our current understanding of ApoE's pleiotropy in multiple brain functions and, of note, reveal the female-specific pathways presumably driven by a sex-dependent, transcriptional role of ApoE.

While their results are informative and very interesting to the AD research community, we would like to suggest the authors to clarify or elaborate a few points, which, in our view, will complement this solid manuscript and better inspire future studies for this underappreciated matter of genderassociated $A D$ risk:

1. The fundamental approach here is to analyze $A P O E$ gene correlates - genes whose expression correlated with that of $A P O E$ - by a built-in function of the aforementioned database online platform, followed by Gene Ontology characterization and pathway enrichment (DAVID). By this approach, the correlation was first computed with normalization to $A P O E$ transcript level change $(=1.0)$. We recommend that the $A P O E$ expression pattern to be examined in different groups, including ApoE genotypes, genders, ages and clinico-pathological stages.

2. To further exploit this valuable database for better insight on the reported results, the 
information regarding the disease severity - CERAD score and Braak stage - can be used to investigate whether the striking ApoE4-positive female pathways operate at an early stage (more likely to be proactive), at a mid-to-late stage (more likely to be reactive) or along the disease progression (like a disease marker).

3. The authors listed a number of $A P O E$-correlated genes that are most differentially expressed in comparison of genders (Figure 3), and most of them represent a well-known cellular function that is important but not conventionally considered to contribute to $A D$ pathogenesis. In the same context of gender-specific ApoE4 effect, do authors mind providing their observation on the expression pattern of other top AD genes (e.g. APP, PSEN1/2, TREM2, etc.) as well as some of risk genes identified in recent GWAS (e.g. Jensen et al., 2019²)? The results may not be of significant difference but will be of great benefit for understanding how ApoE4 contributes to AD pathogenesis in women.

\section{References}

1. Belloy ME, Napolioni V, Greicius MD: A Quarter Century of APOE and Alzheimer's Disease: Progress to Date and the Path Forward.Neuron. 2019; 101 (5): 820-838 PubMed Abstract | Publisher Full Text

2. Jansen IE, Savage JE, Watanabe K, Bryois J, et al.: Genome-wide meta-analysis identifies new loci and functional pathways influencing Alzheimer's disease risk.Nat Genet. 51 (3): 404-413 PubMed Abstract | Publisher Full Text

Is the work clearly and accurately presented and does it cite the current literature? Yes

Is the study design appropriate and is the work technically sound? Yes

Are sufficient details of methods and analysis provided to allow replication by others? Yes

If applicable, is the statistical analysis and its interpretation appropriate?

I cannot comment. A qualified statistician is required.

Are all the source data underlying the results available to ensure full reproducibility? Yes

Are the conclusions drawn adequately supported by the results?

Yes

Competing Interests: No competing interests were disclosed.

Reviewer Expertise: Neuroscience; molecular biology; stem cell biology; neurodegeneration; Alzheimer's disease; aging

We confirm that we have read this submission and believe that we have an appropriate level of expertise to confirm that it is of an acceptable scientific standard, however we have 
significant reservations, as outlined above.

Reviewer Report 30 April 2019

https://doi.org/10.5256/f1000research.20445.r47507

(C) 2019 Ashford J. This is an open access peer review report distributed under the terms of the Creative Commons Attribution License, which permits unrestricted use, distribution, and reproduction in any medium, provided the original work is properly cited.

\section{J.Wesson Ashford}

${ }^{1}$ Department of Psychiatry and Behavioral Sciences, School of Medicine, Stanford University, Stanford, CA, USA

2 Director, WRIISD, VA Palo Alto HCS, Livermore, USA

The article by Hsu et al. is an interesting and worthwhile article.

My 3 problems with such articles are:

Grouping genotypes as e4 positive or negative - the e4/4 group is as different from the e3/4 group as the e3/4 group is from the e3/3 group, and the e2/4 is very similar to e3/3 - so this is poor data analysis.

There is an exponential increase of dementia/Alzheimer rate with age, doubling every 5 years, which is rarely taken into account. Since women live on the average 5 years longer than men, this totally ignored discrepancy can fully account for the male/female difference in Alzheimer incidence, and should definitely be discussed in such studies. Only precise age adjustments with an exponential term can be correctly interpreted. Most such data sets use 5 -year cohorts, which is why this issue is wrongly considered. To really resolve Alzheimer's disease, more precision of simple epidemiological data is needed.

A major issue is Leptin, which has a level twice as high in women as men. Leptin is related to energy metabolism and learning, both important issues in AD.

For yet another perspective, see Smith et al., $2019^{1}$.

\section{References}

1. Smith CJ, Ashford JW, Perfetti TA: Putative Survival Advantages in Young Apolipoprotein $\varepsilon 4$ Carriers are Associated with Increased Neural Stress.J Alzheimers Dis. 2019; 68 (3): 885-923 PubMed Abstract | Publisher Full Text

Is the work clearly and accurately presented and does it cite the current literature? Yes

Is the study design appropriate and is the work technically sound? Partly

Are sufficient details of methods and analysis provided to allow replication by others? Yes 
If applicable, is the statistical analysis and its interpretation appropriate?

Partly

Are all the source data underlying the results available to ensure full reproducibility? Yes

Are the conclusions drawn adequately supported by the results?

No

Competing Interests: No competing interests were disclosed.

Reviewer Expertise: Psychiatry, neuroscience

I confirm that I have read this submission and believe that I have an appropriate level of expertise to confirm that it is of an acceptable scientific standard.

\section{Comments on this article}

\section{Version 1}

Author Response 14 Jul 2019

Anna Delprato, BioScience Project, Wakefield, USA

We would like to thank the reviewers for evaluating our study and for providing many useful suggestions and insights. We have addressed each of the points in our response below and we have submitted a revised version of the manuscript.

Reviewer 1.

The article by Hsu et al. is an interesting and worthwhile article.

My 3 problems with such articles are:

Grouping genotypes as e4 positive or negative - the e4/4 group is as different from the e3/4 group as the e $3 / 4$ group is from the e $3 / 3$ group, and the e2/4 is very similar to e $3 / 3$ - so this is poor data analysis.

We agree totally with this comment. However, as we have now explained in the methods section, only the e4/4 genotype was taken into account and the other possible APOE genotypes/alleles were not considered in the analysis because that genotype information was not available.

We have added more information about the different APOE genotypes in the introduction section.

There is an exponential increase of dementia/Alzheimer rate with age, doubling every 5 years, which is rarely taken into account. Since women live on the average 5 years longer than men, this totally ignored discrepancy can fully account for the male/female difference in Alzheimer incidence, and should definitely be discussed in such studies. Only precise age adjustments with an exponential term can be correctly interpreted. Most such data sets use 5-year cohorts, which is why this issue is wrongly considered. To really resolve Alzheimer's 
disease, more precision of simple epidemiological data is needed.

Thank you for this information. We have raised this point in the discussion section.

A major issue is Leptin, which has a level twice as high in women as men. Leptin is related to energy metabolism and learning, both important issues in AD.

We are working on a follow up study and will have a look at Leptin expression as well as related molecules.

For yet another perspective, see Smith et al., 2019.

1. Smith CJ, Ashford JW, Perfetti TA: Putative Survival Advantages in Young Apolipoprotein $\varepsilon 4$ Carriers are Associated with Increased Neural Stress. J Alzheimers Dis. 2019; 68 (3): 885-923

https://www.ncbi.nlm.nih.gov/pubmed/30814349

Thank you for bringing this article to our attention.

\section{Reviewer 2.}

We recommend that the APOE expression pattern to be examined in different groups, including ApoE genotypes, genders, ages and clinico-pathological stages.

To evaluate $A P O E$ expression patterns among these groups, we performed a repeated measures analysis of variance with genotype and sex as between-subject factors and brain area (frontal white matter, FWM; hippocampus, HIP; parietal cortex, PCx; and temporal cortex, TCX) as a withinsubject factor. As post hoc test for interactions we used Least Squares Means.

There was a marginally significant sex* genotype interaction $[F(1,69)=33.19, P=0.0784]$ and a significant effect for brain area $[F(3,207)=49.83 \mathrm{P}<0.0001]$. These analyses have been added to the results section.

In the same context of gender-specific ApoE4 effect, do authors mind providing their observation on the expression pattern of other top AD genes (e.g. APP, PSEN1/2, TREM2, etc.) as well as some of risk genes identified in recent GWAS (e.g. Jensen et al., 2019)

In addition to $A P O E$, we have analyzed the expression patterns of several other Alzheimer's risk factor genes: APP, PSEN1/2, ADAM10, TREM2 and CNTNAP2. The results are incorporated into the manuscript.

CERAD score and Braak stage - can be used to investigate whether the striking ApoE4positive female pathways operate at an early stage (more likely to be proactive), at a mid-tolate stage (more likely to be reactive) or along the disease progression (like a disease marker).

This is a wonderful suggestion but this evaluation was not possible due to the small sample size of the APOE4+ female group and the multiple DSM-IV indications within. There are seven subjects in this group and based on the DSM-IV clinical diagnosis, 2 have "Alzheimer's", 2 "No Dementia", and 3" Multiple Etiologies". 
We did however analyze the possible relationship between clinico-pathological stages and gene expression patterns for the Alzheimer's risk factor genes among the APOE4+/- females and males. Correlations between Braak stage, CERAD score, and expression of risk factor genes in the four brain regions are now reported in the results section.

The new information and links to the data have been added to the revised version of the manuscript. We hope that the changes made adequately address the concerns raised by the reviewers.

Competing Interests: No competing interests to report.

The benefits of publishing with F1000Research:

- Your article is published within days, with no editorial bias

- You can publish traditional articles, null/negative results, case reports, data notes and more

- The peer review process is transparent and collaborative

- Your article is indexed in PubMed after passing peer review

- Dedicated customer support at every stage

For pre-submission enquiries, contact research@f1000.com 